\title{
Childhood Absence Epilepsy in the Middle Black Sea Region
}

\author{
Sevgi Cirakli1 ${ }^{1(\mathbb{D})}$ \\ ${ }^{1}$ Departmant of Pediatrics, Faculty of Medicine, Division of Pediatric Neurology, Ordu University, Ordu, Turkey \\ Copyright@ Author(s) - Available online at https://dergipark.org.tr/en/pub/mbsjohs \\ Content of this journal is licensed under a Creative Commons Attribution-NonCommercial 4.0 International \\ License,
}

Received: 10 December 2020, Accepted: 23 March 2021, Published online: 30 April 2021

(C) Ordu University Institute of Health Sciences, Turkey, 2021

\begin{abstract}
Objective: The aim of this study was to evaluate chilhood absence epilepsy in the Middle Black Sea Region. Methods: 14 pediatric patients who treated absence epilepsy between May 2018 and May 2020, and had adequate follow-up were included in the study. Medical record datas were reviewed age, gender, etiology, features of family, treatment, and results.
\end{abstract}

Results: 10 (71\%) of the patients were female and 4 (29\%) were male. Their average age was 9 years (6-15). Valproate was started in all patients at the time of diagnosis. In the controls 15 days later, no seizure was detected by the family of 5 patients. 5 patients stated that their seizures decreased but continued. In 4 patients, the family did not notice a decrease in seizure frequency. Ethosuximide was added to 9 patients who said that their seizures were still continuing. In the controls 15 days later, 6 patients were found to be cured. However, it was stated that 3 patients had intermittent seizures although they decreased. Lamutrigine was added as the third drug after checking the valproate drug level to these 3 patients, whose treatment was still unsuccessful. 3 patients still have electroencephalography disorder and seizures recognized by the family. With our treatment management, 11 of 14 patients were found to be seizure free.

Conclusion: We achieved high success with valproate and ethosuximide in the treatment management of pediatric absence epilepsy.

Key words: Absence; epilepsy; childhood; treatment

Suggested Citation: Cirakli S, Childhood absence epilepsy in the middle black sea region childhood absence epilepsy. Mid Blac Sea Journal of Health Sci, 2021; 7(1):38-41

\section{Address for correspondence/reprints:}

Sevgi Cirakli

Telephone number: +90 5338173685

E-mail: sevgigumusoglu@ @otmail.com

\section{Introduction}

Epilepsy is the most common neurological disease of childhood. Absence epilepsies, on the other hand, constitute $10-17 \%$ of childhood epilepsies (1). It is frequently seen between the ages of 4 and 10. Its etiology is unknown, and the genetic basis is thought to be more common than other epilepsies (2). It usually presents as sudden hesitation and freezing. It is defined as loss of consciousness with sudden onset and sudden end (3). The diagnosis is made by clinical and electroencephalography (EEG).

In the treatment, there is a high rate of response to medical treatment. Three drugs come to the fore in the treatment of this disease. These are ethosuximide, valproate and lamotrigine (4). Ethosuximide is used 
in the first stage, valproate and lamuthrigine are used in the second stage $(1,4)$. But we can not get ethosuximide easily in Turkey. So, we have to use the others.

In this article, we aimed to evaluate 14 patients who presented to our hospital with absence epilepsy. In addition, we wanted to present our treatment method in terms of its effectiveness.

\section{Methods}

14 patients who applied to Ordu University Trainind and Research Hospital with absence epilepsy between May 2018 and May 2020 were retrospectively analyzed. Ethics committee approval at Ordu University (ODU KAEK 2020/19/181) was obtained for the study, and the medical records of the cases were examined. Informed consent was waived. All patients were questioned about own/family history, status, additional disease, and medications were evaluated. Since we could not reach ethosuximide, which is the first choice in absence epilepsy at the time of diagnosis, valproate, which is the second choice, was started in all patients. Overseas drug request was made for ethosuximide. Ethosuximide was added to the treatment after 15 days in patients who could not be controlled with valproate. Lamutrigine was added as the third drug to the patients who could not be controlled with the combination of valproate and ethosuximide. The patients were followed by the same pediatric neurologist. Patients who were re-evaluated clinically after one year were included in the study. Patients with insufficient follow-up period were exclusioned in the study

\section{Statistical analysis}

IBM SPSS (Statistical Package for the Social Sciences) Statistics for Windows, version 21.0, was used for analyzing of datas. While evaluating the study dates; caterogical variables were expressed as $n$ (\%), normally distributed continuous variables as mean \pm standard deviation, and non-normally distributed continuous variables, as median and minimum-maximum

\section{Results}

$10(71 \%)$ of 14 cases were female and $4(29 \%)$ were male. Average age was 9 (6-15). It was learned from the families that patients have between 3 to 5 seizure in a day. Since we could not reach ethosuximide, which is the first choice in absence epilepsy, at the time of diagnosis, valproate, the second choice, was started in all patients. A foreign request was made for ethosuximide. In the controls 15 days later, no seizure was detected by the family of 5 patients. 5 patients stated that their seizures decreased but continued. In 4 patients, the family did not notice a decrease in seizure frequency. Ethosuximide was added to the treatment of 9 patients who said that their seizures continued. At the control 15 days later, 3 patients stated that they had intermittent seizures but that they had decreased. Lamigdal was added to the treatment of these 3 patients, whose treatment management was still unsuccessful, after checking the valproate drug level. 3 patients still have EEG disorder and seizures recognized by the family, EEG findings showed 3 -hertz spike wave activities lasting 8-10 seconds. In our treatment management, 11 out of 14 patients $(78 \%)$ were found to be seizure free. Patients who were re-evaluated clinically after one year were included in the study. No other accompanying seizure type was observed during the follow-up. Tandem MS and blood amino acids were sent to all patients for additional metabolic disease and no pathology was detected. Since the patients recovered completely during our follow-up period, there was no patient we terminated the drug treatment.

\section{Discussion}

Epilepsy is one of the most common neurological disorders of childhood. Epilepsy disorders occur at a rate of approximately $40-50 / 100,000$ per year. The risk of seizure is highest in the first year of life. Approximately $20-25 \%$ of all epilepsies are resistant to drug therapy. Childhood absence epilepsy is a wellknown type of epilepsy that is common in childhood and covers $10-17 \%$ of childhood epilepsies (1).

Childhood absence epilepsy appears as a form of idiopathic generalized epilepsies (2). It occurs in developing children between the ages of 4-10. It peaks between the ages of 7-8 (4). The rate of occurrence in girls is higher than in boys. Girls (71\%) made up the majority of the cases in our study, too.

Genetic basis is thought to be more common than other epilepsies (2). It usually presents as sudden hesitation and freezing. Eye blinking or motor automatisms may accompany this condition (4). Typical absence epilepsies happen as often as 10-20 times a day, lasting seconds. It is defined as loss of consciousness with sudden onset and sudden end (5). While myoclonias are observed on one side of the eyelids of the face, myoclonus is rarely observed in the limbs. Usually lasts 9-10 seconds, hyperventilation and photic stimulation are sensitive. In some patients, seizures can be triggered by these warnings (6). 
Absence epilepsies are divided into 2 main groups. These are childhood absence epilepsy, which starts around the age of 6 , and juvenile absence epilepsy that begins at the age of 12 (7). In childhood absence epilepsy, upward sliding of the eyes may generally accompany (5). In juvenile absence epilepsies, loss of consciousness is less than childhood absence epilepsy and myoclonias may accompany with a higher rate than childhood absence epilepsy (8). In our age group, there were cases from the youngest to the age of 6 years and the oldest to 15 years old, and we had cases that we considered as both childhood and juvenile absence epilepsy.

The clinic is often noticed by a teacher or an attentive family member. It is typical to have a sudden pause during normal work. It is short term and lasts within seconds. The diagnosis can be made by a good history, hyperventilation test or typical EEG findings (9). Age group should be considered as diagnosis. For example, glut-1 deficiency should be excluded in a patient with absence epilepsy that started before the age of 4. Because glut-1 deficiency can also come with these findings and its treatment is different (10).

The centrotemporal spike wavy epilepsy of childhood (BECTS) covers $8-20 \%$ of all childhood epilepsies and can be seen with a high rate of childhood absence epilepsy. There are many studies showing their association (3). The mechanism of these two types of epilepsy is thought to be the same (3). At the same time, it has been shown that absence epilepsies may be associated with panayaotoplus, idiopathic and gestaut type occipital epilepsy, myoclonic epilepsy of infancy, juvenile myoclonic epilepsy, lgs, West syndrome (5). In our 1-year follow-up, we did not detect any other seizure type in any of our patients.

Most absence epilepsies respond to medication. Three drugs come to the fore in the treatment of this disease. These are ethosuximide, valproate and lamutrigine. Ethosuximide is used in the first stage, valproate and lamuthrigine are used in the second stage. Etosuximide has been used clinically since 1958. However, its effectiveness has been demonstrated only in absence epilepsy. Genaralized tonic is not effective in clonic or focal motor seizures (4). It is rapidly absorbed from the gastrointestinal tract. Its half-life is approximately $30-40$ hours. It reaches its peak value 4 hours after ingestion and provides stable plasma concentration within 7-10 days (11). Ethosuximide can cause nausea, sedation, diarrhea, ataxia, and extrapyramidal symptoms. Rarely, it has psychological effects such as psychosis and depression. Valproate, on the other hand, is preferred in cases where absence epilepsy is accompanied by generalized tonic-clonic seizures (4). Valproate increases the amount of gaba in the brain. Closes the Na-gated voltage channels. However, it is still unclear how it affects absence epilepsy. It has been observed that ethosuximide and valproate, which are used as monotherapy in the treatment of absence epilepsy, are superior to lamutrigen. Since ethoxuximide preserves attention better than valproate, it would be more appropriate to choose this treatment at the first stage (12).

Treatment success depends on the type of absence epilepsy of the patient and the patient. Remissions generally occur between the ages of 10-14 and sometimes they can be seen at earlier ages $(4,13,14)$.

Seizure free is achieved with drugs in $70 \%$ of absence epilepsies. In accordance with the literature, we achieved seizure free in $78 \%$ of 14 of our patients. It was observed that there was no motor automatism, clinics with pause/gaze and eye involvement were more difficult to control (15). If the EEGs are normal and there is no seizure within 1-2 years after the start of treatment, the drug is tapered and discontinued. In our 1-year follow-up period, the medical treatment of all our patients with absence epilepsy continues. Even if absence epilepsy is diagnosed and treated in a short time, its social and behavioral effects have been mentioned in adulthood (12).

There are also drugs that can aggravate the seizure. Because tiagabine, carbamezapine, oxcarbamezapine, vigabatrin and possibly phenytoin increases absence seizures, it should be avoided from these drugs

\section{Conclusions}

As a result, absence epilepsy is common in the society, especially in the childhood age group. Because it takes a short time, its diagnosis can be delayed. Early recognition and treatment of absence epilepsy cases that respond to medical treatment is very important in children...

Ethics Committee Approval: Ethics committee approval at Ordu University (ODU KAEK 2020/19/181) was obtained for the study.

Peer-review: Externally peer-reviewed.

Author Contributions: Concept, Design, Literature search, Data Collection and Processing, Analysis or Interpretation, Writing: SC.

Conflict of Interest: No conflict of interest was declared by the author.

Financial Disclosure: The author declared that this study hasn't received no financial support. 


\section{References}

1. Loiseau P, Duche B, Pedespan JM. Absence epilepsies. Epilepsia 1995; 36: 1182-1186.

2. Galli J, Micheletti S, Malerba L, Fazzi E, Giordano L. Childhood Absence Epilepsy evolving to Eyelid Myoclonia with Absence. Seizure 2018; 61: 1-3.

3. Verrotti A, Casciato S, Spalice A, Carotenuto M, Striano P, Parisi P, et al. Coexistence of childhood absence epilepsy and benign epilepsy with centyrotemporal spikes: A case series. Eurepean Journal of Paediatric Neurology 2017; 21: 570575.

4. Kessler SK, McGinnis E. A Practical Guide to Treatment of Childhood Absence Epilepsy. Pediatr Drugs 2019; 21: 15-24.

5. Verrotti A, D'Alonzo R, Rinaldi VE, Casciato S, D'Aniello A, Di Gennaro G. Childhood absence epilepsy and benign epilepsy with centro-temporal spikes: a narrative review analysis. World $\mathrm{J}$ Pediatr 2017; 13: 106-111.

6. Hughs JR. Absence seizures: a review of recent reports with new concepts. Epilepsy Behav 2009; 15: 404-412.

7. Cerminara C, Coniglio A, El-Malhany N, Casarelli L, Curatolo P. Two epileptic syndromes, one brain: childhood absence epilepsy and benign childhood epilepsy with centrotemporal spikes. Seizure 2012; 21: 70-74.

8. Aigubella Macau M, Falip Centellas M, Veciana de las Heras M, Climent Perin MA, Miro Llado J, Morone Gomez I, et al. Long term prognosis of juvenile absence epilepsy. Neurologia 2011; 26: 193-199.

9. Carmant L, Kramer U, Holmes GL, Mikati MA, Riviello JJ, Helmers SL. Differantial diagnosis of staring spells in children: a video-EEG study. Pediatr Neurol 1996; 14: 199-202.

10.Larsen J, Johannesen KM, Ek J, Tang S, Marini C, Blichfeldt S, et al. The role of SLC2A1 Mutations in myoclinic astatic epilepsy and absence epilepsy, and the estimated frequency of GLUT1 deficiency syndrome. Epilepsia 2015; 56: 203208.

11.Battino D, Estienne M, Avanzini G. Clinical pharmocokinetics of antiepileptic drugs in paediatric patients. Part I: phenobarbital, primidone, valproic acid, ethosuximide and mesuximide. Clin Pharmocokinet 1995; 29: 257 286.

12. Cnaan A, Shinnar S, Arya R, Adamson PC, Clark $\mathrm{PO}$, Dlugos D, et al. Second monotherapy in childhood absence epilepsy. Neurology 2017; 88: 182-190.
13. Sato S, Dreifuss FE, Penry JK, Kirby DD, Palesch Y. Long-term follow-up of absence seizures. Neurology 1983; 33: 1590-1595.

14.Wirrell EC, Camfield CS, Camfield PR, Gordon KE, Dooley JM. Long-term prognosis of typical childhood absence epilepsy: remission or progression to juvenile myoclonic epilepsy. Neurology 1996; 47: 912-918.

15. Kessler SK, Shinnar S, Cnaan A, Dlugos A, Conry J, Hirtz DG, et al. Pretreatment seizure semiology in childhood absence epilepsy. Neurology 2017; 89: 673-679. 